\title{
Autosomal dominant hyperinsulinism due to Kir6.2 deficiency
}

INSERM

\section{Source}

INSERM. (1999). Orphanet: an online rare disease and orphan drug data base. Autosomal dominant hyperinsulinism due to Kir6.2 deficiency. ORPHA:276580

Autosomal dominant hyperinsulinism due to Kir6.2 deficiency is a form of diazoxidesensitive diffuse hyperinsulinism (DHI) characterized by hypoglycemic epiosodes that are usually mild, escaping detection during infancy, and usually a good clinical response to diazoxide, (but some are diazoxide resistant). Autosomal dominant hyperinsulinism due to Kir6.2 deficiency usually has a milder phenotype when compared to that resulting from recessive K+ (K-ATP) channel mutations (Recessive forms of diazoxide-resistant hyperinsulinism, see this term). 